\title{
Overexpression of dominant-negative Ikaros 6 isoform is associated with resistance to TKIs in patients with Philadelphia chromosome positive acute lymphoblastic leukemia
}

\author{
CHANGFENG SHAO $^{1}$, JIE YANG $^{2}$, YIRONG KONG ${ }^{3}$, CONG CHENG $^{1}$, \\ WEI LU ${ }^{4}$, HONGZAI GUAN ${ }^{4}$ and HAIYAN WANG ${ }^{1}$ \\ Departments of ${ }^{1}$ Transfusion and ${ }^{2}$ Hematology, The Affiliated Hospital of Qingdao University, Qingdao, \\ Shandong 266003; ${ }^{3}$ Department of The Clinical Laboratory, Qingdao Municipal Hospital, Qingdao, Shandong 266000; \\ ${ }^{4}$ Department of Hematology, Medical College of Qingdao University, Qingdao, Shandong 266071, P.R. China
}

Received January 3, 2017; Accepted August 2, 2017

DOI: 10.3892/etm.2017.4941

\begin{abstract}
The clinical significance of the dominant-negative Ikaros 6 (DN-IK6) in the treatment of patients with Philadelphia-positive acute lymphoblastic leukemia $\left(\mathrm{Ph}^{+}-\mathrm{ALL}\right)$ with tyrosine kinase inhibitors (TKIs) remains elusive. In the present study, it was demonstrated that DN-IK6 was overexpressed in B-cell (B)-ALL cases compared with T cell-ALL cases at the mRNA and protein levels. Furthermore, nucleotide sequencing revealed that DN-IK6 was due to the deletion of IKAROS family zinc finger 1 exons 4-7. The outcome of patients with $\mathrm{Ph}^{+}-\mathrm{B}-\mathrm{ALL}$ with DN-IK6, and treated with TKIs and hyper-cyclophosphamide/vincristine/doxorubicin/dexamethasone regimen were restrospectively evaluated in a 2 year follow-up. The results demonstrated that those with the DN isoform exhibited significantly lower incidences of remission, shorter median cumulative incidence of relapse times $(\mathrm{P}<0.05)$ and shorter median overall survival times $(\mathrm{P}<0.05)$ compared with those without the DN isoform. In conclusion, the results of the present study demonstrated that DN-IK6 is overexpressed in the majority of patients with $\mathrm{Ph}^{+}$-ALL, and is significantly associated with resistance to TKI therapy.
\end{abstract}

\section{Introduction}

The $\mathrm{Ph}$ chromosome is found in 20 to $30 \%$ of adults with acute lymphoblastic leukemia (ALL) (1). As the first generation

Correspondence to: Professor Hongzai Guan, Department of Hematology, Medical College of Qingdao University, 308 Ningxia Road, Qingdao, Shandong 266071, P.R. China

E-mail: guanhongzai@163.com

Professor Haiyan Wang, Department of Transfusion, The Affiliated Hospital of Qingdao University, 16 Jiangsu Road, Qingdao, Shandong 266003, P.R. China

E-mail: why_phd@163.com

Key words: Ikaros, leukemia, dominant-negative, TKIs, $\mathrm{Ph}$ chromosome of specific BCR-ABL inhibitors, imatinib chemotherapy produces a very high complete remission in patients with $\mathrm{Ph}$ chromosome positive acute lymphoblastic leukemia $\left(\mathrm{Ph}^{+}-\mathrm{ALL}\right)$, however, the minority of patients did not benefit from this treatment, due to drug resistance or intolerance (2).

Ikaros is a member of a family of zinc finger transcription factors, it plays an important role in the control of hematopoietic differentiation and proliferation, particularly in lymphoid cell lineage (3-6). Normal Ikaros, such as the IK1 isoform has a central DNA-binding domain consisting of four zinc fingers and a homo-and hetero-dimerization domain consisting of the two carboxy-terminal zinc fingers (7). By alternative splicing, the Ikaros gene encodes at least twelve functionally distinct zinc finger proteins whose expression has different IK. If the well-characterized DN-IK6 isoform lacks any of the $\mathrm{N}$-terminal zinc fingers, it is not capable of binding to DNA and acts as a dominant-negative (DN). The isoform has been shown to be highly expressed in leukemia patients, particularly in cases of $\mathrm{Ph}^{+}-\mathrm{ALL}$, and has been related to clinical diagnosis, therapeutic effects and prognosis $(6,7)$.

Since its discovery, several groups of international experts in this field have made tremendous advances in understanding the function of DN-IK6 at the molecular, cellular, and biological levels, as well as in elucidating the clinical significance of these findings in ALL patients (8). Mullighan et al (9) investigated 304 individuals with ALL, including 43 cases of BCR-ABL1 B-progenitor ALL, suggested that DN isoform resulted from IKZF1 gene deletions. The conclusion was that the deletion was an important event in the development of BCR-ABL1 ALL. Furthermore, another study (10) found that IKZF1 deletions were associated with a very poor outcome in a cohort of 221 children with high-risk B-cell-progenitor ALL. Despite these findings, the role of the DN-IK6 isoform and non-DN-IK6 isoform in TKIs plus hyper-CVAD chemotherapy regimen and VDCP chemotherapy (such as vincristine, doxorubicin, cyclophosphamide and prednisone) has not been extensively systematically discussed or reported. In this article, we sought to detect the expression of DN-IK6 in B-ALL patients and determine the relationship between DN-IK6 isoform and TKIs combined chemotherapy regimen. 


\section{Materials and methods}

Patients. Based on the MICM (Morphology, Immunology, Cytogenetics, Molecular biology) classification (WHO, 2008), all the patients were diagnosed. Between July 2010 and July 2014, bone marrow and peripheral blood samples from 82 B-ALL patients and 24 T-ALL. B-ALL patients were retrospectively studied (totally 46 male and 36 female; median age, 43 years; range, 18 to 68 years) after informed consent. Five healthy adult volunteers' samples served as normal controls. As previous reported the human B-cell precursor leukemia BV-173 cell line lacking the four NH2-terminal DNA-binding zinc fingers expressed the same sequence as the DN-IK6 isoform. Furthermore, the BV-173 cell line was used for positive controls from DSMZ (German Collection of Microorganisms and Cell Cultures, Braunschweig, Germany). All cells were cultured in RPMI-1640 supplemented with $10 \%$ fetal bovine serum, $2 \%$ glutamine and $1 \%$ penicillin-streptomycin (Gibco/Invitrogen, Karlsruhe, Germany) at $37^{\circ} \mathrm{C}$ with $5 \% \mathrm{CO}_{2}$ (11-13). The study was approved by Ethics Committee of hospital and all the participants signed in formed consent. All the clinical data of patients were show in Table I.

Methods. All samples were prepared according to the standard procedure using R-banding (12). A total of 20 metaphase cells derived from the unstimulated bone marrow of each patient were analyzed. Karyotypes were described according to the international system for human cytogenetic nomenclature (ISCN2005) (14). $\mathrm{Ph}^{+}-\mathrm{B}-\mathrm{ALL}$ patients received TKIs plus hyper-CVAD (hyperfractionated cyclophosphamide, vincristine, adriamycin, dexamethasone) treatment, while the $\mathrm{Ph}$-B-ALL patients received VDCP (such as vincristine, doxorubicin, cyclophosphamide and prednisone) treatment. After remission, all patients were treated with each regimen for approximately 24 months sequentially. All the patients had received four courses of chemotherapy, and accepted follow-up every month by the end of 2014 .

Reverse transcription-polymerase chain reaction (RT-PCR) and Sequencing analysis. Firstly, Mononuclear cells were obtained by Ficoll Hypaque density gradient centrifugation and all samples were stored at $-80^{\circ} \mathrm{C}$. Then, Total cellular RNA was extracted from cells using the RNeasy total RNA isolation kit (Invitrogen, Shanghai, China) as recommended by the manufacturer. According to the instructions of the manufacturer, Total RNA $(5 \mu \mathrm{g})$ was heat denatured at $65^{\circ} \mathrm{C}$ for $5 \mathrm{~min}$ in the presence of $0.5 \mu \mathrm{g}$ of oligo (dT) 18 primer (Thermo Fisher Scientific, Inc., Waltham, MA, USA) and chilled on ice. The denatured RNA was reverse transcribed in $20 \mu 1$ of final volume of $4 \mu 15 \mathrm{X}$ Reaction Buffer, $1 \mu 1$ Ribolock RNase Inhibitor, $10 \mathrm{mM}$ of each dNTP, $1 \mu 1$ Revert Aid M-MuLV Reverse Transcriptase (Thermo Fisher Scientific, Inc.). The reaction mixture was incubated at $42^{\circ} \mathrm{C}$ for $1 \mathrm{~h}$ and then at $70^{\circ} \mathrm{C}$ for $5 \mathrm{~min}$. The reverse transcription reaction product was stored at $-80^{\circ} \mathrm{C}$. Finally, the expression of Ikaros isoforms was examined by RT-PCR analysis with the following primers: F5'-CGACGCACAAATCCACAT AA-3' and R5'-GCAGCAGCAGGTTCTCCAC-3'. The IK6 primers were tested for their specificity to ensure no other ikaros isoforms were amplified before we started the experiment. PCR conditions were as follows: $95^{\circ} \mathrm{C}$ for $5 \mathrm{~min}$ for denaturation, then $95^{\circ} \mathrm{C}$ for $30 \mathrm{sec}, 62^{\circ} \mathrm{C}$ for $30 \mathrm{sec}$, and $72^{\circ} \mathrm{C}$ for $7 \mathrm{~min}$ repeated for 35 cycles, followed by $72^{\circ} \mathrm{C}$ for $10 \mathrm{~min}$. The RNA integrity was confirmed by PCR amplification of the GAPDH mRNA.

Amplifications for the gene was performed by an optimized protocol recommended by the manufacturer (10 min at $95^{\circ} \mathrm{C}, 40$ repeated cycles of two steps at $95^{\circ} \mathrm{C}$ for $15 \mathrm{sec}, 62^{\circ} \mathrm{C}$ for $60 \mathrm{sec}$ and $72^{\circ} \mathrm{C}$ for $30 \mathrm{sec}$ ). All of the RT-PCR products were purified and subsequently analyzed by direct sequencing using an Applied Biosystems 3730 automated DNA sequencer from the Jin Sirui biotechnology company (Invitrogen; Thermo Fisher Scientific, Inc.). The resultant sequence data were compared with reference genome sequence data obtained from the NCBI to prove the existence of the deletions of IKZF1 gene exons 4-7. The sequence comparison was used with the BLAST software tool and standard sequence (Gene bank ID: NM006060).

Western blot analysis. Whole cell lysates were separated on a 4-12\% SDS-polyacrylamide gel and transferred onto a polyvinylidene fluoride (PVDF) membrane (Invitrogen; Thermo Fisher Scientific, Inc) with a glycine transfer buffer $(150 \mathrm{mM}$, 1.0\% Nonidet P-40, 5 mM EDTA, $50 \mathrm{mM}$ Tris-HCl, $\mathrm{pH}$ 7.5). After blocking the nonspecific site with 5\% non-fat dry milk, the membrane was incubated with the specific primary antibody (Santa Cruz Biotechnology, Inc., Santa Cruz, CA, USA) in $3 \% \mathrm{BSA}$ at $4^{\circ} \mathrm{C}$ overnight. The membrane was further incubated for $60 \mathrm{~min}$ with a peroxidase-conjugated secondary antibody (1:2,000; Santa Cruz Biotechnology, Inc.) at room temperature. The targeted proteins were detected using the WEST-ZOL (plus) Western Blot Detection System (iNtRON, Gyeonggi, Korea). The $\beta$-actin was used as a control.

Quantitative PCR ( $q P C R)$. Based on these findings, the correlation between pretherapy and remission of patients with DN-IK6 isoform was investigated, qPCR (Roche, Shanghai, China) analysis for the expression quantity of DN-IK6 isoform was performed using the previouse primers in the same samples and at the same time-points in 21 cases expressing $\mathrm{DN}$ isoform. Because of the low expression stability, GAPDH was measured as the internal control in this experimental setting at the same time. The GAPDH primer pair (Forward: 5'-CAAGGTCATGACAACTTTG-3' and Reverse: 5'-GTC CACCACCCTGTTGCTGTAG-3') was designed by the Shanghai Sangon Company. The comparative $\Delta \mathrm{Cq}$ method was employed to evaluate the expression quantity of DN-IK6 isoform (15). Depending on the qPCR instruments, the PCR mixture contained $50 \mathrm{ng}$ of template, $0.3 \mu \mathrm{M}$ forward primer, $0.3 \mu \mathrm{M}$ reverse primer, $25 \mu 1$ Fast Start Universal SYBR-Green Master and $19 \mu \mathrm{l} \mathrm{PCR}$-grade water (Fermentas, Thermo Fisher Scientific, Inc., Pittsburgh, PA, USA) on an ABI instrument. Gene amplification was performed using an optimized protocol recommended by the manufacturer.

Statistical analysis. We estimated the differences in the initial percentage of remission in four weeks using the Fisher's exact test. Cumulative incidence of relapse (CIR) was measured from the date of first complete hematologic response (CHR) 
Table I. Clinical data of the patients in the three groups.

\begin{tabular}{lccc}
\hline Characteristics & $\begin{array}{c}\text { B-ALL } \\
(\mathrm{n}=82)\end{array}$ & $\begin{array}{c}\text { T-ALL } \\
(\mathrm{n}=24)\end{array}$ & $\begin{array}{c}\text { Normal } \\
(\mathrm{n}=5)\end{array}$ \\
\hline Mean age (years) & 43 & 40 & 35 \\
Range age (years) & $18-68$ & $20-65$ & $24-50$ \\
Males & 46 & 14 & 3 \\
Females & 36 & 10 & 2 \\
$\mathrm{Ph}^{+}$patients & 28 & 7 & 0 \\
Ph $^{-}$patients & 54 & 17 & 0 \\
Patients with DN-IK6 & 21 & 0 & 0 \\
\hline
\end{tabular}

ALL, acute lymphoblastic leukemia; $\mathrm{Ph}^{+}$, Philadelphia-positive; $\mathrm{Ph}^{-}$ Philadelphia negative; DN-IK6, dominant-negative Ikaros 6.

Table II. Correlation of Ikaros 6 expression with clinical characteristics in patients with B-ALL (mean \pm SD).

\begin{tabular}{lccc}
\hline Characteristics & $\begin{array}{c}\text { Ikaros 6 } \\
(\mathrm{n}=21)\end{array}$ & $\begin{array}{c}\text { Ikaros 6- } \\
(\mathrm{n}=61)\end{array}$ & $\mathrm{P}$ \\
\hline Male (n) & 14 & 35 & 0.607 \\
Female (n) & 7 & 26 & \\
Age (years) & $38.81 \pm 16.42$ & $36.07 \pm 15.27$ & 0.488 \\
WBC $\left(\mathrm{x} 10^{9} / 1\right)$ & $51.64 \pm 82.68$ & $87.68 \pm 19.05$ & 0.405 \\
PLT $\left(\times 10^{12} / 1\right)$ & $128.12 \pm 133.16$ & $118.91 \pm 124.34$ & 0.733 \\
Blasts \% & $83.20 \pm 8.90$ & $70.32 \pm 24.74$ & 0.023 \\
\hline
\end{tabular}

ALL, acute lymphoblastic leukemia; WBC, white blood cell; PLT, platelet count; SD, standard deviation.

to the date of hematologic relapse at 24 months, censoring patients alive in CR. Overall survival (OS) was measured from the date of diagnosis until death from any cause or the deadline of follow-up. Kaplan-Meier curves were used to assess CIR and OS, and differences between groups were compared using the log rank test. P-values less than 0.05 were considered to be statistically significant. Not significant (NS) indicate $\mathrm{P}>0.05$. All statistical calculations, graphs were performed and constructed using SPSS soft (Version 17.0; SPSS, Inc., Chicago, IL, USA). The expression levels of DN-IK6 isoform were evaluated as quantification cycle $(\mathrm{Cq})$ values. The $2^{-\Delta \Delta \mathrm{Cq}}$ method was used to analyze the expression difference of DN-IK6 isoform between pretherapy and remission samples (15).

\section{Results}

Clinical characteristics of patients with $B-A L L$. Comprehensive clinical data were also collected. We observed that the percentage of blast cells in the B-ALL patients with DN-IK6 isoform was higher than that in the patients without the DN-IK6 (83.20 \pm 8.90 vs. $70.32 \pm 24.74, \mathrm{P}<0.05)$. However, there were no significant differences in age, sex, white blood cell (WBC) and platelet count (PLT) at the time of diagnosis.
The correlations between DN isoform and clinical characteristics in this cohort are shown in Table II.

DN-IK6 isoform expression in ALL patients. Based on the cytogenetic analysis, $28 \mathrm{Ph}^{+}$patients and $54 \mathrm{Ph}^{-}$patients were examined from a total of $82 \mathrm{~B}$-ALL patients. Using RT-qPCR, we detected expression levels of IK in 106 cases of adult ALL. Compared with Ph-B-ALL patients (4/50, $8 \% ; \mathrm{P}<0.05)$, bone marrow cells expressed more DN-IK6 in $\mathrm{Ph}^{+}$-ALL patients $(17 / 28,60.71 \%)$. The DN-IK6 isoform were not found in the patients with T-ALL (0/18). In contrast, expression of the DN-IK6 isoform was not found in 5 normal volunteers.

The sequencing analysis and western blot analysis of DN-IK6 isoform. The DN-IK6 isoform that lacks the DNA-binding domain but has the $\mathrm{C}$-terminal zinc fingers was caused by a deletion of exons 4-7 in IKZF1. The mutations were confirmed by sequencing analysis (Fig. 1) in 21 patients with the DN-IK6. The expression of the DN-IK6 protein was confirmed using western blot analysis in bone marrow cells from all the patients with DN-IK6 isoform and in BV-173 cells. The positions corresponding to the migration patterns of IKZF1 (58KD), IKZF2 (47KD), and DN-IK6 and BV-173 cell (36 KD) proteins are indicated. The lysates were also analyzed with an $\beta$-actin (42KD) and as a control. (Fig. 2) Figs. 1 and 2 are the representative result of sequencing and western blot.

The expression of quantity DN-IK6 isoform in pretherapy and remission. The result shows that the expression of DN-IK6 isoform in pretherapy samples was approximately three times more than that of the remission samples using the mean $\mathrm{Ct}$ value (Table III). Every result was obtained via a melting curve analysis to confirm the specificity of amplification and lack of primer dimmers.

DN-IK6 isoform expression is associated with the percentage of remission. In $\mathrm{Ph}^{+}-\mathrm{ALL}$ patients, treated with TKIs plus hyper-CVAD, the percentage of remission in the patients with DN-IK6 was lower than that without DN-IK6 (17.65 vs. 90.91\%, $\mathrm{P}<0.05)$. While in $\mathrm{Ph}-\mathrm{ALL}$ patients, treated with DVCP, the percentage of remission in the patients with DN-IK6 was also lower than that of the patients without DN-IK6 (50 vs. 84\%, NS).

DN-IK6 isoform expression is correlated with unfavorable prognostic. The $\mathrm{Ph}^{+}$-ALL patients with DN-IK6 tended to have shorter median CIR times than those without DN-IK6 (7 months vs. 20 months, 95\% CI: 3.97 to 12.03 and 8.05 to 33.95, respectively, log-rank $\chi^{2}=6.33, \mathrm{P}<0.05$ ) (Fig. 3). Similarly, the $\mathrm{Ph}$-ALL patients with DN-IK6 tended to have shorter median CIR times than those without DN-IK6 (8 months vs. 18 months; 95\% CI: 0 to 16.82 and 11.07 to 24.93 ; respectively log-rank $\left.\chi^{2}=1.15, \mathrm{NS}\right)$. Additionally, the $\mathrm{Ph}^{+}$-ALL patients with DN-IK6 tended to have shorter median OS times than those without DN-IK6 (14 months vs. 23 months, 95\% CI: 11.69 to 18.31 and 16.08 to 23.92 , respectively, log-rank $\chi^{2}=3.901, \mathrm{P}<0.05$ ) (Fig. 4). Similarly, the Ph-ALL patients with DN-IK6 tended to have shorter median OS times than those without DN-IK6 (13 vs. 24 months; $95 \%$ CI: 8.69 to 23.82 and 17.18 to 20.86 ; respectively log-rank $\left.\chi^{2}=3.13, \mathrm{NS}\right)$. Taken together, we observed 


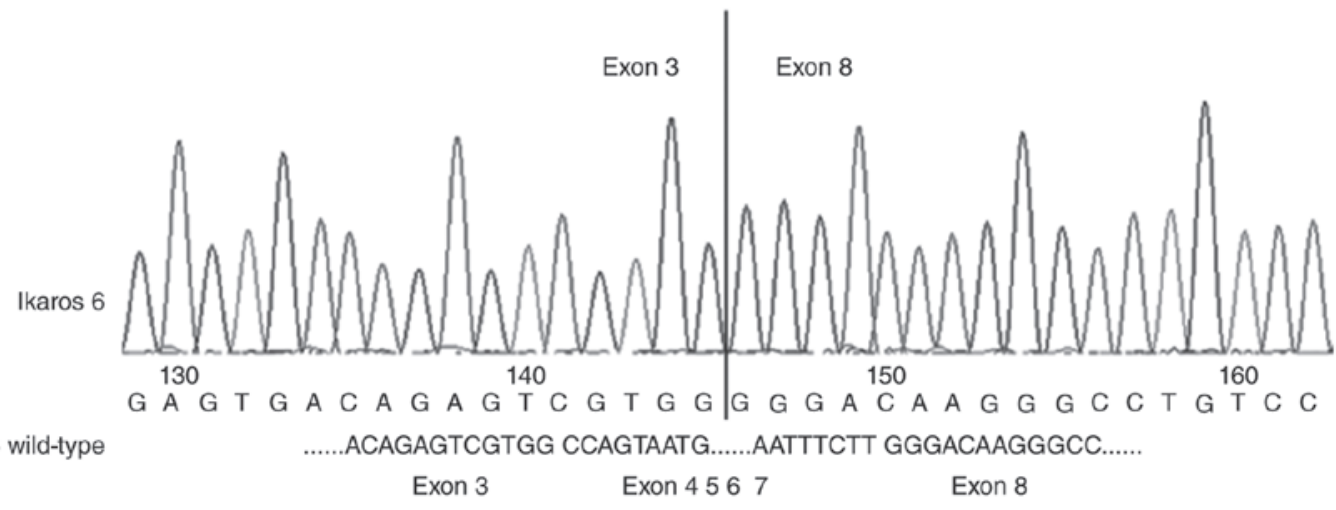

Figure 1. All the patients with dominant-negative Ikaros 6 isoform is mainly due to a deletion of exons 4-7 of the IKZF1 gene.

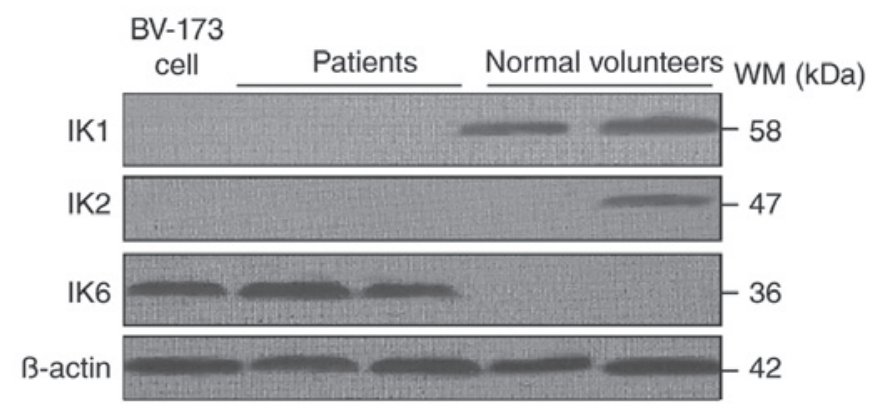

Figure 2. Different Ikaros (IK) protein were confirmed by western blot analysis. The column 1 represents the human B-cell precursor leukemia BV-173 cell (36KD) for positive control. The columns 2-3 represent the patients with IK6 (36KD). The columns 4-5 represent the normal volunteers with IKZF1 (58KD) and IKZF2 (47KD). The $\beta$-actin (42KD) was used as a control.

a lower incidence of remission, CIR times and OS times in the $\mathrm{Ph}^{+}$-ALL patients with DN-IK6 isoform.

\section{Discussion}

The present studies showed that DN-IK6 played a critical regulatory role in the differentiation of hematopoietic cells and demonstrated a high frequency expression in leukemia, particularly in ALL patients with $\mathrm{Ph}^{+}$chromosome. In accordance with the studies $(11,16,17)$, the aberrant isoform lacking all $4 \mathrm{~N}$-terminal zinc-fingers responsible for DNA-binding was found to be over expressed in $\mathrm{Ph}^{+}$-ALL patients compared with $\mathrm{Ph}^{-}$-ALL patients. Our data also revealed that deletions in exons 4-7 of the IKZF1 gene primarily led to the DN-IK6. As a tumor suppressor in human leukemia (18), the presence of DN Ikaros mutant activity may be a pivotal step in the development of ALL. We hypothesized that the function of Ikaros may represent an important potential treatment method in patients with DN-IK6 isoform in the future.

Focusing on the patients with the DN-IK6 isoform, we demonstrated that the expression of DN-IK6 isoform was obviously decreased in the remission samples according to RQ-PCR. Thus, we considered that DN-IK6 isoform could be regarded as a predictive recover index in $\mathrm{Ph}^{+}-\mathrm{ALL}$.

Several studies, including those conducted by Vignetti et al (19) and Delannoy et al (20) have reported the activity of TKIs in $\mathrm{Ph}^{+}$-ALL. With the use of TKI alone or in association with conventional chemotherapy, the percentage of complete hematologic remission (CHR) could be obtained in 98 to $100 \%$ of patients with $\mathrm{Ph}^{+}$-ALL (19). In addition, Sima Jeha et al (21) reported that TKIs administered in the early phases of therapy can dramatically reduce MRD and improve outcome of childhood $\mathrm{Ph}^{+}$-ALL. However Iacobucci et al and Martinelli et al $(11,16)$ reported a previously unclear link between the resistance to TKIs and the expression of DN-IK6 isoform in $\mathrm{Ph}^{+}-\mathrm{ALL}$ patients. Recently, Mullighan et al (22) suggested that the expression of DN-IK6 isoform was associated with an unfavorable prognostic outcome in B-ALL. Moreover, Liu et al (17) demonstrated that the expression of DN-IK6 isoform may contribute to poor response to chemotherapy and was inversely correlated with the achievement of CHR at an early time point. Therefore, we conducted the present study to explore the difference between the DN-IK6 group (treated with TKIs plus hyper-CVAD) and the non-DN-IK6 group (treated with DVCP). Although Iacobucci et al (11) reported that transfection of DN-IK6 isoform in an Imatinib-sensitive DN-IK6 isoform negative $\mathrm{Ph}^{+}$-ALL cell line decreased sensitivity to TKIs, little is known about the relevance of the differences between DN-IK6 isoform and non-DN-IK6 isoform in regard to the resistance to TKIs plus hyper-CVAD and DVCP. Our data indicated that TKIs plus hyper-CVAD chemotherapy was relatively good therapeutic regimen and achieved the unsatisfactory effect for the $\mathrm{Ph}^{+}$-ALL patients. Nevertheless, the reason that the same treatment was capable of inducing very positive responses such as high HCR rate, prolonged survival probability, and even overall survival (OS) in patients with a median age of 69 years remains unknown (19). Whether this diversity is due to the difference in race and median age patients (China vs. Italy, 46 vs. 69) needs to be further determined in the next study. On the other hand, our result shows that $\mathrm{Ph}^{+}$-ALL patients with DN-IK6 isoform were obviously resistant to TKIs, which was the most effective treatment at present for the type of disease. Although, no statistical significance was found in the $\mathrm{Ph}^{-}$-ALL patients with DN-IK6 isoform in this study, we still drew a speculation that $\mathrm{Ph}^{-}$-ALL patients treated with DVCP, the percentage of remission in patients with DN-IK6 was lower than that of the patients without DN-IK6, and needed further study in more patients.

We also analyzed the association between statistical indicators (CIR and OS) and DN-IK6 isoform in B-ALL patients. Compared with the $\mathrm{Ph}^{+}$-ALL patients without DN-IK isoform, we observed a higher rate of CIR and a lower rate of OS in the 
Table III. Clinical and laboratory characteristics of the patients with the DN-IK6 isoform.

\begin{tabular}{|c|c|c|c|c|c|c|c|c|}
\hline Case & Age & Sex & Diagnosis & Cytogenetic analysis & $\begin{array}{c}\text { Pretherapy } \\
\qquad \Delta \mathrm{Cq} \\
\text { values }\end{array}$ & $\begin{array}{c}\text { Remission } \\
\Delta \mathrm{Cq} \\
\text { values }\end{array}$ & $\begin{array}{l}\Delta \Delta \mathrm{Cq} \\
\text { values }\end{array}$ & $\begin{array}{l}2^{-\Delta \Delta \mathrm{Cq}} \\
\text { values }\end{array}$ \\
\hline 1 & 26 & $\mathrm{~F}$ & ALL-L1 & 46,xy,t(9;22)(q34;q11)add(20)(q11) & 3.36 & 4.72 & -1.36 & 2.57 \\
\hline 2 & 26 & $\mathrm{~F}$ & ALL-L2 & $\begin{array}{l}49, \mathrm{x}, \operatorname{dic}(\mathrm{y} ; 14)(\mathrm{q} 12 ; \mathrm{q} 32), \mathrm{t}(9 ; 22)(\mathrm{q} 34 ; \mathrm{q} 11), \\
-9,+\operatorname{der},(22) \mathrm{t}(9 ; 22),+3\end{array}$ & 4 & 4.46 & -0.46 & 1.38 \\
\hline 3 & 55 & $\mathrm{M}$ & ALL-L2 & $46, x y, t(9: 22)(q 34: q 11)$ & 2.46 & 3.73 & -1.27 & 2.41 \\
\hline 4 & 55 & M & ALL-L2 & $46, x y, t(5 ; 18)(q 14 ; q 23), t(9 ; 22)(q 34 ; q 11)$ & 3.6 & 4.54 & -0.94 & 1.92 \\
\hline 5 & 47 & $\mathrm{M}$ & ALL & $46, x y, t(9 ; 22)(q 34 ; q 11)$ & 3.3 & 5.44 & -2.14 & 4.41 \\
\hline 6 & 54 & $\mathrm{M}$ & ALL-L3 & $46, x y$, ins $(13 ; 14)(q 31: q 22), t(9 ; 22)(q 34 ; q 11)$ & 4.9 & 5.96 & -1.06 & 2.08 \\
\hline 7 & 32 & $\mathrm{~F}$ & ALL & $46, x y, t(9 ; 22)(q 34 ; q 11)$ & 2.32 & 3.78 & -1.46 & 2.75 \\
\hline 8 & 28 & $\mathrm{M}$ & ALL & $46, x y, t(9 ; 22)(q 34 ; q 11)$ & 4.34 & 5.68 & -1.34 & 2.53 \\
\hline 9 & 51 & $\mathrm{~F}$ & ALL-L1 & 46,xy,t(9;22)(q34;q11)add(19)(p13) & 4.72 & 6.21 & -1.49 & 2.81 \\
\hline 10 & 26 & $\mathrm{~F}$ & ALL & $46, x y, t(9 ; 22)(q 34 ; q 11)$ & 2.32 & 4.8 & -2.48 & 5.58 \\
\hline 11 & 46 & $\mathrm{~F}$ & ALL-L1 & $45, x y, t(9 ; 22)(q 34 ; q 11),-20$ & 3.86 & 5.86 & -2 & 4.00 \\
\hline 12 & 18 & M & ALL-L1 & $46, x y, t(4 ; 111)(q 21 ; q 23), t(9 ; 22)(q 34 ; q 11)$ & 2.07 & 4.27 & -2.2 & 4.59 \\
\hline 13 & 34 & $\mathrm{M}$ & ALL-L1 & $47, \mathrm{xy},+\mathrm{x}, \mathrm{tt}(9 ; 22)(\mathrm{q} 34 ; \mathrm{q} 11)$ & 3.5 & 5.86 & -2.36 & 5.13 \\
\hline 14 & 36 & M & ALL & $46, x y, t(9 ; 22)(q 34 ; q 11)$ & 4.33 & 5.67 & -1.34 & 2.53 \\
\hline 15 & 38 & $\mathrm{~F}$ & ALL-L1 & $46, x x, t(9 ; 22)(q 34 ; q 11)$, & 2.38 & 5.74 & -3.36 & 10.27 \\
\hline 16 & 42 & $\mathrm{~F}$ & ALL-L3 & $46, x x, t(9 ; 22)(q 34 ; q 11)$ & 3.67 & 5.61 & -1.94 & 3.84 \\
\hline 17 & 44 & $\mathrm{~F}$ & ALL-L2 & $46, \mathrm{xx}, \mathrm{t}(9 ; 22)(\mathrm{q} 34 ; \mathrm{q} 11)$ & 3.44 & 5.31 & -1.87 & 3.66 \\
\hline 18 & 46 & M & ALL & 46,xy,i(q)(q10) & 2.97 & 6.17 & -3.2 & 9.19 \\
\hline 19 & 34 & $\mathrm{~F}$ & ALL-L1 & $46, \mathrm{xx}, \mathrm{t}(1 ; 19)(\mathrm{q} 23 ; \mathrm{p} 13)$ & 3.56 & 5.5 & -1.94 & 3.84 \\
\hline 20 & 39 & $\mathrm{~F}$ & ALL-L2 & $46, \mathrm{xx}, \mathrm{t}(4 ; 15 ; 6)(\mathrm{p} 15 ; \mathrm{q} 14 ; \mathrm{q} 22)$ & 3.14 & 5.85 & -2.71 & 6.54 \\
\hline 21 & 51 & $\mathrm{M}$ & ALL-L1 & $46, x y,(3 ; 22)(p 25 ; q 11)$ & 2.87 & 5.02 & -2.15 & 4.44 \\
\hline Mean & & & & & 3.39 & 5.25 & -1.86 & 3.63 \\
\hline
\end{tabular}

ALL, acute lymphoblastic leukemia; M, male; F, female; pretherapy $\Delta \mathrm{Cq}$ values, the expression quantity of dominant-negative Ikaros 6 (DN-IK6) isoforms was performed before pretherapy; remission $\Delta \mathrm{Cq}$ values, the expression quantity of DN-IK6 isoforms was performed after hematologic response; $\Delta \Delta \mathrm{Cq}$ values, the difference between the pretherapy $\Delta \mathrm{Cq}$ values and the post-treatment $\Delta \mathrm{Cq}$ values. The $2^{-\Delta \Delta \mathrm{Cq}}$ method was used to analyze the expression difference of DN-IK6 isoform between pretherapy and remission patients. The result shows that the expression of DN-IK6 isoform in pretherapy samples was approximately three times more than that of the remission samples using the mean Cq value.

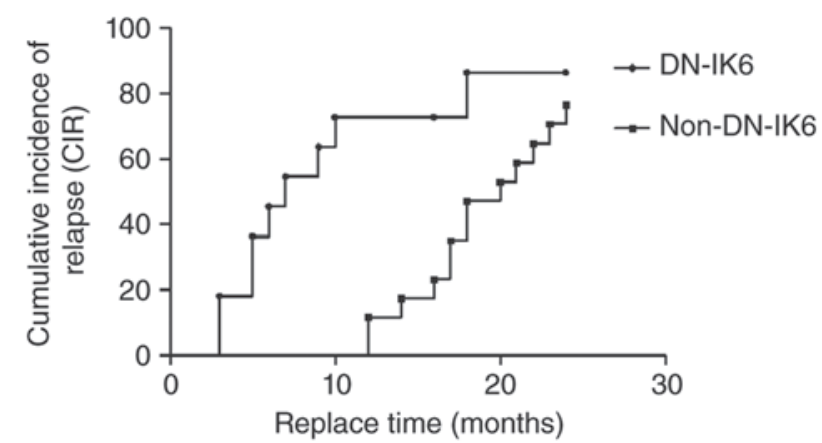

Figure 3. Kaplan-Meier estimate of cumulative incidence of relapse (CIR) of Philadelphia-positive acute lymphoblastic leukemia $\left(\mathrm{Ph}^{+}-\mathrm{ALL}\right)$ patients. The CIR time of patients with dominant-negative Ikaros 6 (DN-IK6) isoform $(n=17)$ was significantly higher than those without IK6 isoform $(n=11)$ in the patients with $\mathrm{Ph}^{+}-\mathrm{ALL}$. $\left(\log\right.$-rank $\left.\chi^{2}=5.50, \mathrm{P}<0.05\right)$. The status means the censored data of two groups, which were DN-IK6 group and the non-DN-IK6 group in the patients with $\mathrm{Ph}^{+}-\mathrm{ALL}$.

patients with DN-IK6 isoform, and suffered a higher relapse rate within the follow-up period. Our results also clearly indicated

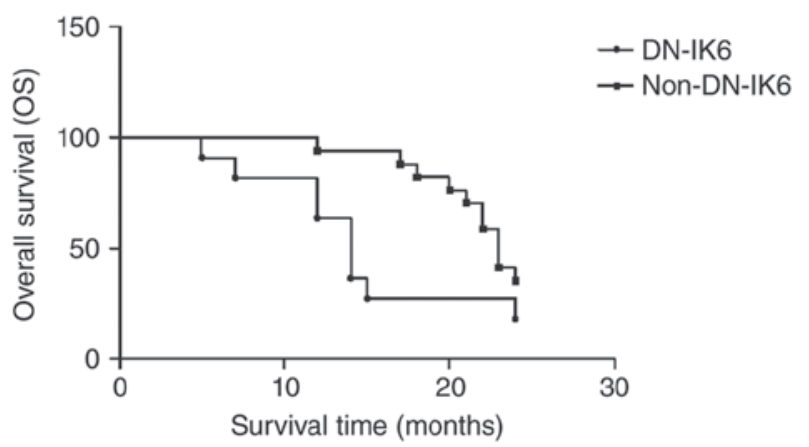

Figure 4. Kaplan-Meier estimate of overall survival (OS) of Philadelphia-positive acute lymphoblastic leukemia $\left(\mathrm{Ph}^{+}-\mathrm{ALL}\right)$ patients The OS time of patients with dominant-negative Ikaros 6 (DN-IK6) isoform $(n=17)$ was significantly lower than those without IK6 isoform $(n=11)$ in the patients with $\mathrm{Ph}^{+}-\mathrm{ALL}\left(\log\right.$-rank $\left.\chi^{2}=4.613, \mathrm{P}<0.05\right)$. The status means the censored data of the two groups, which were DN-IK6 group and the non-DN-IK6 group in the patients with $\mathrm{Ph}^{+}-\mathrm{ALL}$.

that the DN-IK6 played a critical regulatory role in the hematopoietic system, especially in cases of $\mathrm{Ph}^{+}-\mathrm{B}-\mathrm{ALL}$. The conclusion 
is in accordance with the view proposed by Zhou, et al (23). Their study suggests that DN-IK6 may be a biological marker of chemosensitivity and relapse and DN-IK6 may provide a potential therapeutic strategy for ALL (23). Intensive study of DN-IK6 isoform in human leukemic cells has indicated a close correlation between the reduced function of IK 1 orIK 2 and the clonal expansion of hematopoietic cells, leading to overt malignancies (18). However, the pathogenesis of $\mathrm{Ph}^{+}-\mathrm{B}-\mathrm{ALL}$ patients with DN-IK6 isoform remains unclear, but may be likely to the following two factors: First, repression of c-Myc is critical for Ikaros and Aiolos to exert their growth-inhibitory effect on pre-B-cells. Aiolos and Ikaros fail to inhibit pre-B-cell proliferation in the presence of sustained c-Myc expression (24); and second, ALL patients are characterized by JAK mutations, IKAROS/IKZF1 deletions, and BCR-ABL1-like signatures, as well as other DNA deletions. The combination of genomic abnormalities may cooperate to promote leukemogenesis and contribute to the exceedingly poor outcome (25).

Although an unexpected relevance of the rate of CIR and $\mathrm{OS}$ between $\mathrm{Ph}^{-}$-ALL patients with $\mathrm{DN}$ isoform and non-DN isoform was found in the present study, we did find that both of the groups had a short median CIR and OS times. This outcome may be due to an insufficiency of $\mathrm{Ph}^{-}$-ALL patients with DN isoform. In summary, our data demonstrated that the expression of DN-IK6 isoform in $\mathrm{Ph}^{+}$-ALL patients was associated with the short median CIR times and OS times.

In conclusion, our data confirmed that the DN-IK6 isoform, which is caused by a deletion of exons 4-7 in the IKZF1 gene, is highly expressed in $\mathrm{Ph}^{+}$-ALL patients. Moreover, we demonstrated that $\mathrm{Ph}^{+}$-ALL patients with $\mathrm{DN}$-IK6 isoform were obviously resistant to TKIs.

\section{Acknowledgements}

The authors would like to thank all the participants for the study.

\section{References}

1. Cytogenetic abnormalities in adult acute lymphoblastic leukemia: Correlations with hematologic findings outcome. A Collaborative Study of the Group Français de Cytogénétique Hématologique. Blood 87: 3135-3142, 1996.

2. Kantarjian H, Sawyers C, Hochhaus A, Guilhot F, Schiffer C, Gambacorti-Passerini C, Niederwieser D, Resta D, Capdeville R, Zoellner U, et al: Hematologic and cytogenetic responses to imatinib mesylate in chronic myelogenous leukemia. N Engl J Med 346: 645-652, 2002.

3. Winandy S, Wu L, Wang JH and Georgopoulos K: Pre-T cell receptor (TCR) and TCR-controlled checkpoints in T cell differentiation are set by Ikaros. J Exp Med 190: 1039-1048, 1999.

4. Umetsu SE and Winandy S: Ikaros is a regulator of I110 expression in CD4 ${ }^{+} \mathrm{T}$ cells. J Immunol 183: 5518-5525, 2009.

5. Sun L, Liu A and Georgopoulos K: Zinc finger-mediated protein interactions modulate Ikaros activity, a molecular control of lymphocyte development. EMBO J 15: 5358-5369, 1996.

6. Kano G, Morimoto A, Takanashi M, Hibi S, Sugimoto T, Inaba T, Yagi T and Imashuku S: Ikaros dominant negative isoform (Ik6) induces IL-3-independent survival of murine pro-B lymphocytes by activating JAK-STAT and up-regulating Bcl-xl levels. Leuk Lymphoma 49: 965-973, 2008.

7. Sezaki N, Ishimaru F, Takata M, Tabayashi T, Nakase K Kozuka T, Fujii K, Nakayama H, Teshima T, Harada M and Tanimoto M: Over-expression of the dominant-negative isoform of Ikaros confers resistance to dexamethasone-induced and anti-IgM-induced apoptosis. Br J Haematol 121: 165-169, 2003.
8. Dovat S: Ikaros in hematopoiesis and leukemia. World J Biol Chem 2: 105-107, 2011.

9. Mullighan CG, Miller CB, Radtke I, Phillips LA, Dalton J, Ma J, White D, Hughes TP, Le Beau MM, Pui CH, et al: BCR-ABL1 lymphoblastic leukaemia is characterized by the deletion of Ikaros. Nature 453: 110-114, 2008.

10. Medeiros BC: Deletion of IKZF1 and prognosis in acute lymphoblastic leukemia. N Engl J Med 360: 1787-1788, 2009.

11. Iacobucci I, Lonetti A, Messa F, Cilloni D, Arruga F, Ottaviani E, Paolini S, Papayannidis C, Piccaluga PP, Giannoulia P, et al: Expression of spliced oncogenic Ikaros isoforms in Philadelphia-positive acute lymphoblastic leukemia patients treated with tyrosine kinase inhibitors: Implications for a new mechanism of resistance. Blood 112: 3847-3855, 2008.

12. Nakase K, Ishimaru F, Avitahl N, Dansako H, Matsuo K, Fujii K, Sezaki N, Nakayama H, Yano T, Fukuda S, et al: Dominant negative isoform of the Ikaros gene in patients with adult B-cell acute lymphoblastic leukemia. Cancer Res 60: 4062-4065, 2000.

13. Nakayama H, Ishimaru F, Avitahl N, Sezaki N, Fujii N, Nakase K, Ninomiya Y, Harashima A, Minowada J, Tsuchiyama J, et al: Decreases in Ikaros activity correlate with blast crisis in patients with chronic myelogenous leukemia. Cancer Res 59: 3931-3934, 1999.

14. Gonzalez Garcia JR and Meza-Espinoza JP: Use of the international system for human cytogenetic nomenclature (ISCN). Blood 108: 3952-3953, 2006.

15. Livak KJ and Schmittgen TD: Analysis of relative gene expression data using real-time quantitative PCR and the 2(-Delta Delta C (T)) method. Methods 25: 402-418, 2001.

16. Martinelli G, Iacobucci I, Storlazzi CT, Vignetti M, Paoloni F, Cilloni D, Soverini S, Vitale A, Chiaretti S, Cimino G, et al: IKZF1 (Ikaros) deletions in BCR-ABL1-positive acute lymphoblastic leukemia are associated with short disease-free survival and high rate of cumulative incidence of relapse: A GIMEMA AL WP report. J Clin Oncol 27: 5202-5207, 2009.

17. Liu P, Lin Z, Qian S, Qiao C, Qiu H, Wu Y, Li J and Ge Z: Expression of dominant-negative Ikaros isoforms and associated genetic alterations in Chinese adult patients with leukemia. Ann Hematol 91: 1039-1049, 2012.

18. Winandy $\mathrm{S}, \mathrm{Wu} \mathrm{P}$ and Georgopoulos $\mathrm{K}$ : A dominant mutation in the Ikaros gene leads to rapid development of leukemia and lymphoma. Cell 83: 289-299, 1995.

19. Vignetti M, Fazi P, Cimino G, Martinelli G, Di Raimondo F, Ferrara F, Meloni G, Ambrosetti A, Quarta G, Pagano L, et al: Imatinib plus steroids induces complete remissions and prolonged survival in elderly Philadelphia chromosome-positive patients with acute lymphoblastic leukemia without additional chemotherapy: Results of the Gruppo Italiano Malattie Ematologiche dell'Adulto (GIMEMA) LAL0201-B protocol. Blood 109: 3676-3678, 2007.

20. Delannoy A, Delabesse E, Lhéritier V, Castaigne S, Rigal-Huguet F, Raffoux E, Garban F, Legrand O, Bologna S, Dubruille $\mathrm{V}$, et al: Imatinib and methylprednisolone alternated with chemotherapy improve the outcome of elderly patients with Philadelphia-positive acute lymphoblastic leukemia: Results of the GRAALL AFR09 study. Leukemia 20: 1526-1532, 2006.

21. Jeha S, Coustan-Smith E, Pei D, Sandlund JT, Rubnitz JE, Howard SC, Inaba H, Bhojwani D, Metzger ML, Cheng C, et al: Impact of tyrosine kinase inhibitors on minimal residual disease and outcome in childhood Philadelphia chromosome-positive acute lymphoblastic leukemia. Cancer 120: 1514-1519, 2014.

22. Mullighan CG, Su X, Zhang J, Radtke I, Phillips LA, Miller CB, Ma J, Liu W, Cheng C, Schulman BA, et al: Deletion of IKZF1 and prognosis in acute lymphoblastic leukemia. N Engl J Med 360: 470-280, 2009.

23. Zhou F, Xu Y, Qiu Y, Wu X, Zhang Z and Jin R: Ik6 expression provides a new strategy for the therapy of acute lymphoblastic leukemia. Oncol Rep 31: 1373-1392, 2014.

24. Ma S, Pathak S, Mandal M, Trinh L, Clark MR and Lu R: Ikaros and Aiolos inhibit pre-B-cell proliferation by directly suppressing c-Myc expression. Mol Cell Biol 30: 4149-4158, 2010.

25. Harvey RC, Mullighan CG, Wang X, Dobbin KK, Davidson GS, Bedrick EJ, Chen IM, Atlas SR, Kang H, Ar K, et al: Identification of novel cluster groups in pediatric high-risk B-precursor acute lymphoblastic leukemia with gene expression profiling: Correlation with genome-wide DNA copy number alterations, clinical characteristics and outcome. Blood 116: 4874-4884, 2010. 